\title{
ТАКТИКА ВЕДЕНИЯ ПАЦИЕНТОВ С ГЕНДЕРНОЙ ДИСФОРИЕЙ: ВЗГЛЯД ЭНДОКРИНОЛОГА
}

\author{
Давиденко И.Ю., Волкова Н.И.
}

ФГБОУ ВО Ростовский государственный медицинский университет Минздрава России, Ростов-на-Дону

ЦЕЛЬ: оценка особенностей назначения гормональной терапии и дальнейшего мониторинга пациентов с гендерной дисфорией.

МАТЕРИАЛЫ И МЕТОДЫ: в исследование включено 10 пациентов с диагнозом гендерная дисфория, верифицированная психиатром на основании Диагностического и статистического руководства по психическим расстройствам (DSM-5). Всем больным проведена оценка состояний, которые могли усугубиться вследствие гормональной абляции и гормонзаместительной терапии выбранного пола до начала лечения. Далее 8 пациентам FtM-трансгендерам была назначена терапия заместительная терапия тестостероном, а 2 пациентам MtF-трансгендерам - препараты эстрогенов и антиандрогены. У всех больных проводился контроль эффективности и безопасности гормональной терапии каждые 3 месяца в течение 1 года лечения согласно клиническим рекомендациям Эндокринного общества: Эндокринная терапия гендерной дисфории/гендерной неконформности.

РЕЗУЛЬТАТЫ: все пациенты соблюдали полученные рекомендации по заместительной терапии и контролю ее эффективности и безопасности. У 8 пациентов FtM-трансгендеров были достигнуты целевые значения уровня общего тестостерона в течение 6-9 месяцев. Также у всех больных, получающих заместительную терапию тестостероном, отмечалось прекращение менструаций к 6 месяцам, и появление вирилизирующих эффектов к 12 месяцам. Побочных эффектов у данных пациентов выявлено не было. Среди пациентов MtF-трансгендеров у 1 человека к 6 месяцам были достигнуты целевые значения эстрадиола и снижение уровня общего тестостерона. Также у него отмечалось появление феминизирующих эффектов к 6-9 месяцам терапии. У 1 пациента MtF-трансгендера не были достигнуты целевые значения эстрадиола на фоне приема максимально допустимой дозы эстрогенов к 9 месяцам, в результате чего пациент самостоятельно стал менять режимы терапии и был исключен из исследования.

ВЫвОды: коррекция пола, безусловно, является сложной задачей, успех решения которой во многом зависит от мультидисциплинарной команды. Перед назначением гормонального лечения эндокринолог должен убедиться, что пациент соответствует критериям диагноза гендерной дисфории. Сама терапия FtM-трансгендеров основывается на принципахлечения мужчин с гипогонадизмом. Эндокринная терапия MtF-трансгендеров включает в себя помимо эстрогенов еще и препараты с антиандрогенным действием. Не вызывает сомнений необходимость регулярного клинического контроля физических изменений и потенциальных неблагоприятных последствий в ответ на гормональное лечение, а также лабораторного мониторинга уровня половых стероидных гормонов каждые 3 месяца в течение первого года терапии.

КЛЮЧЕВЫЕ СЛОВА: Эндокринная терапия; гендерная дисфория; гендерная неконформность; трансгендер 